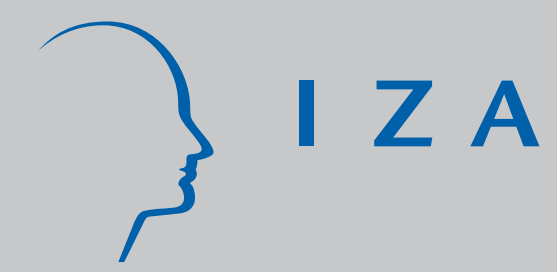

IZA DP No. 1413

Why Is the Public Sector More Labor-Intensive? A Distortionary Tax Argument

Panu Poutvaara

Andreas Wagener

November 2004 


\title{
Why Is the Public Sector More Labor-Intensive? A Distortionary Tax Argument
}

\author{
Panu Poutvaara \\ CEBR, CESifo \\ and IZA Bonn \\ Andreas Wagener \\ University of Vienna, \\ CESifo and CEBR
}

\section{Discussion Paper No. 1413 \\ November 2004}

\author{
IZA \\ P.O. Box 7240 \\ 53072 Bonn \\ Germany
}

\author{
Phone: +49-228-3894-0 \\ Fax: +49-228-3894-180 \\ Email: iza@iza.org
}

\begin{abstract}
Any opinions expressed here are those of the author(s) and not those of the institute. Research disseminated by IZA may include views on policy, but the institute itself takes no institutional policy positions.

The Institute for the Study of Labor (IZA) in Bonn is a local and virtual international research center and a place of communication between science, politics and business. IZA is an independent nonprofit company supported by Deutsche Post World Net. The center is associated with the University of Bonn and offers a stimulating research environment through its research networks, research support, and visitors and doctoral programs. IZA engages in (i) original and internationally competitive research in all fields of labor economics, (ii) development of policy concepts, and (iii) dissemination of research results and concepts to the interested public.
\end{abstract}

IZA Discussion Papers often represent preliminary work and are circulated to encourage discussion. Citation of such a paper should account for its provisional character. A revised version may be available directly from the author. 
IZA Discussion Paper No. 1413

November 2004

\section{ABSTRACT}

\section{Why Is the Public Sector More Labor-Intensive? A Distortionary Tax Argument}

Government-run entities are often more labor-intensive than private companies, even with identical production technologies. This need not imply slack in the public sector, but may be a rational response to its wage tax advantage over private firms. A tax-favored treatment of public production precludes production efficiency. It reduces welfare when labor supply is constant. With an elastic labor supply, a wage tax advantage of the public sector may improve welfare if it allows for a higher net wage. This would counteract the distortion of labor supply arising from wage taxation. Full privatization is never optimal if the labor supply elasticity is positive but small.

JEL Classification: L33, J45, D24, H21

Keywords: public sector, labor intensity, taxation

Corresponding author:

Panu Poutvaara

CEBR

Copenhagen Business School

Porcelaenshaven, Bldg 65

DK-2000 Frederiksberg

Denmark

Email: panu.poutvaara@cebr.dk 


\section{Introduction}

The main thrust of outsourcing and privatization is efficiency: government-run enterprises or services often are thought to absorb substantial portions of the state budget without generating commensurate contributions to social welfare. Moreover, lack of competition and incentives, X-inefficiency, a soft budget constraint, and the failure to properly price inputs and outputs may result in significant misallocation of resources and welfare losses. Privatization and outsourcing of government activities have been essential in transforming former socialist economies. Also many market economies have chosen to privatize public utilities and state-owned enterprises or to outsource parts of government activities to the private sector (e.g., telephone services, waste collection and treatment, public transport, hospitals, and prisons). ${ }^{1}$ Over the last 10 to 15 years, central government employment (excluding teachers and workers in the health sector) in OECD countries decreased from 2.9 to $1.9 \%$ of the population and the governmental wage bill decreased from 5.5 to $4.4 \%$ of GDP (Schiavo-Campo et al., 2003).

Privatization and outsourcing often result in lower labor inputs in the privatized firms (for a survey see Megginson and Netter 2001). In a study on 63 privatizations, Dewenter and Malatesta (2001) report a significant decline in labor intensity after privatization. In a study on 218 privatizations in Mexico, La Porta and Lòpez-de-Silanes (1999) found that output on average increased by $54.3 \%$ while employment declined by almost half, which indicates a tremendous increase in labor productivity. ${ }^{2}$ This is largely regarded as evidence that, under government-ownership, there had been overmanning and slack working practices, inefficiencies that private firms could not afford under the pressure of the marketplace.

While from everyday experience we would not dismiss the inefficiency hypothesis for the public sector entirely, we propose in this paper a different explanation why private firms have leaner workforces than state-run firms: They operate under a different tax structure with respect to factor inputs.

\footnotetext{
${ }^{1}$ For a survey on state-ownership and privatization in the Western world, see the edited volume by Toninelli (2000).

${ }^{2}$ An empirical investigation by Megginson et al. (1994) does, however, indicate an opposite effect on employment: In their sample of 18 countries they find that privatization on average was followed by a rise in employment.
} 
Consider an economy with wage taxes. For a private firm, this means that if its workers should earn a certain net wage, the firm faces a higher labor cost (namely, the gross wage) of which the tax goes to the government. If the employing unit is state-owned and its recruiting staff fully sees through the government's budgeting, then the employees' net wage reflects the full labor cost for the government - since, by consolidating accounts, all intra-government tax payments net out. Thus, the government incurs a lower labor cost than a private firm and will hire a larger workforce than a private firm that produces the same level of output. Moreover, production in the tax-preferred realm of government is, ceteris paribus and in monetary terms, less costly than production in the private sector.

However, reasoning under the ceteris-paribus-assumption might be quite misleading in this context: Nationalizations or privatizations may impact on factor prices, output in other sectors, factor supplies, budgetary needs, and the tax rate necessary to finance government expenditure. Therefore, a general-equilibrium framework seems more appropriate.

In this paper, we study the effects of allocating parts of an economy's production to the government sector where the employment of labor enjoys a tax advantage relative to the private sector. In particular, we consider a two-sector economy where one of the sectors is always privately organized while the other one - call it sector 1 - can be either government-controlled, privately-run, or anything in between. Real-world examples for such a sector include hospitals, schools, public transportation, and utilities. We assume that output in this sector is provided to citizens free of charge by the government, being financed by a wage tax which has a distortionary effect on labor supply.

For sake of exposition, consider two extreme scenarios for this economy: one where sector 1 is operated by private firms (private economy) and one where it is entirely run by the government (mixed economy). In the private economy, the output from this sector will be purchased by the government. In the mixed economy, the government needs tax revenues in order to remunerate the factors of production that it hires. In either scenario, a balanced government budget is required, and the output is provided for free to the citizens.

Since employment by the government is effectively not subject to labor taxation, production in sector 1 will ceteris paribus exhibit a higher labor intensity in the mixed than in the private economy. We show that this pattern is not only a partial-equilibrium effect 
but also emerges when comparing the general equilibria of the mixed and the private economy, taking into account all adjustments in factor allocations, prices, and the wage tax. As an interesting feature of such a comparison we observe that the equilibrium net wage may (but need not) be higher in the mixed than in the private economy. In that case, the mixed economy will operate with a higher labor supply than the private economy. In principle, this would enable the mixed economy to produce a higher level of output than the private economy. However, this advantage may not materialize: Due to the government's tax advantage the allocation of factors across the two sectors in the mixed economy is distorted away from production efficiency, a requirement that is met in a private economy. This implies a deadweight loss in output, relative to potential output in an efficient intersectoral allocation of resources.

Hence, society faces a trade-off between production efficiency (realized in the private economy) and small tax distortions (realized in the mixed economy). We identify conditions (in terms of the elasticity of labor supply) such that either welfare loss is preferable to the other. In particular, we identify cases where it is optimal (in the second-best sense) to deviate from full privatization and, thereby, to entertain one sector in the economy with a labor intensity that would appear inefficiently high under market conditions.

We assume that government entities take wage and interest levels as given. When hiring labor, the government recognizes that it receives back (or is exempt from paying) at least some part of the taxes that a private firm would have to pay for the same sort of operations. Clearly, the tax asymmetry between the government and the private sector can take on different degrees: A fully centralized government whose officials perfectly see through the consolidated state budget would recognize that, in effect, it does not carry any tax burden at all. However, the government need not be that monolithic:

- First, the organization of public production may be spread over different ministries or departments, each of them being small relative to the whole government. Staff recruiters in these agencies may only partially see through to consolidated government budgets, and the cost accounting in their agencies may be based on statutory rather than net factor costs. The perceived tax advantage for the government would then be smaller than the full tax rate. Similar effects would occur when the government does not operate a single and consolidated accounting but comprises entities with separate budgets (e.g., social insurance agencies, pension schemes etc.). 
- Alternatively, consider a federal economy where public production takes place at a lower level such that only parts of the total tax on labor accrues to, and therefore is irrelevant from the perspective of, the employing jurisdiction. For such federal settings, there is some evidence that local governments are responsive to tax incentives, for example as concerns the VAT treatment of their activities. Wassenaar and Gradus (2004) compare its effect on outsourcing for seven EU countries and Norway. They find that a refund scheme for VAT costs of local governments facilitates outsourcing.

- Finally, varying degrees for the tax advantage of the government over private firms may result from different types of employment. In many countries, people working for the government are separated into civil servants and "normal" employees, for whom standard labor legislation applies (see, e.g., Cardona, 2002). In some countries (e.g., in Germany, Italy, and Austria), civil servants do not pay social security taxes (old-age income, unemployment, or health insurance), or pay only to a lesser extent, while employees typically do. This prima facie makes civil servants the less costly staff type to the government, limiting, however, the government's tax advantage to the degree to which it relies on civil servants as its personnel.

In our model we introduce a parameter that measures the degree of the government's (perceived) tax advantage. The two scenarios compared above represent the extreme cases of a zero or a full tax advantage, where the case of a zero advantage is equivalent to a fully private economy. Intermediate values may capture, in a stylized way, different institutional arrangements in government organization.

While we will more thoroughly relate our approach to existing literature on public production and taxation in the next section, we would like to emphasize one distinctive feature of our approach right here: We assume that production in sector 1 will always be organized efficiently (i.e., in a cost-minimizing way), regardless of whether the sector is privatized or government operated. Thus, the increase in labor intensity that sector 1 encounters when moving from the private sector to the government is not due to waste or slack in the public sector, but merely a consequence of the government's tax advantage. Consequently, the inefficiency that prevails in a mixed economy does not stem from a poor factor allocation within the sector under government ownership but is rather induced by 
tax wedges between public and private sectors. As we show, incurring such inefficiency may be welfare-optimal if it is more than offset by a beneficial reduction of labor supply distortions.

The rest of our paper is organized as follows: Section 2 reviews related literature. Section 3 presents the model. In Section 4 we then derive the differences in factor allocations, factor prices, and tax rates that result from the different organizational modes in a mixed and in a private economy. Section 5 reports our main findings on welfare comparisons. Section 6 concludes.

\section{Related Literature}

An extensive literature discusses why private firms are more productive than public enterprises (for a survey, see Shleifer, 1998). Most popular is a Alchian-Demsetz type propertyrights argument: Since there is no residual claimant in public enterprises, nobody really cares about its efficiency. Hence, workers slack off. Other explanations for the perceived inefficiency of the public sector range from political interference over the pursuit of objectives that are unrelated to efficiency to soft budget constraints and monopoly power in the output market. As observed in Mintz et al. (2000), taxation is a largely overlooked issue in the debate on privatization. Independently of any other effects, differential tax treatment between public and private sector amounts to substantial differences in effective marginal tax rates that, upon organizational changes from private to public (or vice versa), would necessitate a re-allocation of factors of production. Tax issues are a concern of private firms which, when competing against public firms, often complain that tax treatment for public firms is more favorable, thereby giving them an artificial competitive advantages over investor-owned firms. Economists would add that differential tax treatment of firms generates distortions and inefficiencies. ${ }^{3}$

In this paper we look at the relationship between privatization and taxation from a general-equilibrium perspective. Such a view is hardly ever taken in the literature - with

\footnotetext{
${ }^{3}$ In their case study on the (planned, but never accomplished) privatization of Ontario Hydro, a Canadian electricity company, Mintz et al. (2000) illustrate this for the case of capital, land and property taxes in the province of Ontario. However, by ignoring revenue impacts for the government and under a strict ceteris paribus clause, the focus in Mintz et al. (2000) is on the incentives in re-structuring the firm rather than on an overall assessment of the tax issue.
} 
three notable exceptions to which our contribution is related:

In a model where a range of production activities can, with different technologies, be carried out by either the government or by the private sector, Huizinga and Nielsen (2001) investigate the optimal boundary between public and private production. Their focus is on capital income taxation (which distorts private investment decisions), but the analysis can be recast as to deal with labor income taxes. ${ }^{4}$ Huizinga and Nielsen (2001) predict that the size of the public sector, measured by the range of activities that are carried out through the state, is larger the higher is the budgetary need for, or the marginal damage resulting from, distortionary taxation. Moreover, privatization would generally go along with a decrease in the use of the taxed factor. For a simpler economy, our paper comes to quite similar conclusions - but without having to resort to differences in the efficiencies of private and public production. In our framework, outsourcing may be beneficial or counterproductive even when the government and the private sector employ the same production technologies.

Gordon et al. (1999) argue that organizing production in an inefficient government sector may be acceptable for society when the deadweight loss of taxation is sufficiently large. They argue that the inefficiency of the public sector is less than proportionately related to its size while the efficiency costs of taxation increase more than proportionately with the tax rate. At some point, nationalization of industries gets cheaper than financing government purchases through distortionary taxation. This result rests on an in-built inefficiency in the government sector. As mentioned earlier, public production in our model is assumed to be efficiently organized. Rather, the inefficieny in our model is an intersectoral one: For efficiency, sectors should not face different factor price ratios - but in a mixed economy with one sector being private and the other public they do in the presence of non-uniform factor taxation.

In Gordon (2003), the focus is on the role of state-owned banks and capital income taxation. The presence of the latter causes an underinvestment problem in the economy which (even inefficiently organized) state-owned banks can help to remedy by providing cheap loans. Gordon also suggests that public firms may be more labor-intensive than

\footnotetext{
${ }^{4}$ Huizinga and Nielsen (2001) predict over-capitalization of the public sector in the presence of capital income taxes. This is at odds with reality which is characterized by an under-capitalized public sector (see also Gordon, 2003). Replacing capital by labor taxation would, however, render the model's forecasts compatible with reality.
} 
private ones when the government uses its firms to hire workers that would otherwise be unemployed, or to hire unskilled workers to drive up their equilibrium wage. We assume that factor markets are competitive, a condition under which the model developed by Gordon (2003) would not generate any positive role for public ownership. Our model allows such a role since we endogenize labor supply which may then be distorted by taxation. On the other hand also our model predicts that a fully private economy is always optimal with an exogenous labor supply.

\section{The Model}

\subsection{Production}

Consider a closed economy with two sectors $i=1,2$. Sector $i$ uses labor $L_{i}$ and capital $K_{i}$ to produce its output; there are no intermediate inputs. Technologies are represented by neoclassical production functions $F^{i}=F^{i}\left(L_{i}, K_{i}\right)$ which are assumed to have the standard monotonicity and concavity properties. Denoting partial derivatives by subscripts, we assume, in particular, that $F_{L}^{i}>0, F_{K}^{i}>0, F_{L L}^{i}<0, F_{K K}^{i}<0$, and $F_{L L}^{i} F_{K K}^{i}-\left(F_{K L}\right)^{2} \geq 0$ for all $\left(L_{i}, K_{i}\right) \in R_{++}^{2}$.

We assume that the supply of capital is fixed at some level $\bar{K}$. Full employment of capital therefore requires that

$$
K_{1}+K_{2}=\bar{K}
$$

always holds. We denote the rental price of capital by $r$ and the gross wage by $w$. Private employers pay a fraction $t$ of wages to the government as a wage tax. Workers, thus, earn a net wage of $w(1-t)$ per unit of labor supply.

We assume that sector 2 is always privately run and operating in a profit-maximizing way. Profits in sector 2 amount to

$$
\Pi_{2}=F^{2}\left(L_{2}, K_{2}\right)-r \cdot K_{2}-w \cdot L_{2} .
$$

Profit maximization requires that marginal productivities equal factor prices (subscripts to production functions indicate partial derivatives):

$$
\begin{aligned}
& F_{L}^{2}\left(L_{2}, K_{2}\right)=w \\
& F_{K}^{2}\left(L_{2}, K_{2}\right)=r .
\end{aligned}
$$


Sector 1 can be either government-operated or privately-run (think, e.g., of hospitals). We assume that the sector has to provide a certain and invariant level $\bar{F}^{1}$ of output:

$$
F^{1}\left(L_{1}, K_{1}\right) \geq \bar{F}^{1}
$$

We assume that production is organized in a cost-minimizing manner. This is a prerequisite for profit maximization and therefore appears to be an appropriate hypothesis if the sector is in private hands. Assuming cost efficiency in the public sector might be more controversial, given ample evidence for governmental slack. We use the assumption of cost efficiency in order to deliberately rule out all reasons for outsourcing that might arise from an inefficient organization of the public sector.

- If the sector is privately-run, then the cost-minimization problem reads as:

$$
\min _{L_{1}, K_{1}}\left\{r K_{1}+w L_{1} \mid F^{1}\left(L_{1}, K_{1}\right) \geq \bar{F}^{1}\right\}
$$

To assess labor costs, the private firm uses the gross, tax-inclusive wage rate. The FOCs for cost efficiency are given by:

$$
\frac{F_{L}^{1}\left(L_{1}, K_{1}\right)}{F_{K}^{1}\left(L_{1}, K_{1}\right)}=\frac{w}{r}
$$

and the output requirement (4).

- If the sector is government-operated, the cost-minimization problem reads as:

$$
\min _{L_{1}, K_{1}}\left\{r K_{1}+w(1-t) L_{1} \mid F^{1}\left(L_{1}, K_{1}\right) \geq \bar{F}^{1}\right\}
$$

The difference to the private-sector problem is that the government can use the net wage rate $w(1-t)$ to assess labor costs. When deciding on factor demands the organizers of production in the government sector, thus, take gross and net wages as given but regard the government (or the entity to which they are hiring) as being effectively tax-exempt. Such a view would emerge if the recruiter, somewhat heroically, recognized that taxes paid by government entities cancel out entirely upon consolidation of all government accounts. The FOCs for cost efficiency in the government sector are given by:

$$
\frac{F_{L}^{1}\left(L_{1}, K_{1}\right)}{F_{K}^{1}\left(L_{1}, K_{1}\right)}=\frac{w(1-t)}{r}
$$

and, again, the output requirement (4). 
Generalizing (5) and (6), we introduce parameter $\alpha \in[0,1]$ to measure the extent to which the government has, or its authorities that recruit staff into government services perceive the government to have, a relative tax advantage over the private sector: $\alpha=0$ would be equivalent to the outsourcing production of good 1 to the private sector, while with $\alpha=1$ the public sector fully sees through its accounting mechanisms. Variable $\alpha$ may reflect the degree to which employees in government-run entities are exempt from taxes or contributions that are collected in the private sector.

With some leap of faith in the existence of aggregate production functions, one might also interpret $\alpha$ as the fraction of sector 1 that is government-operated. Such an interpretation might be appropriate for the case of public transport, where only parts of the network might be operated through private companies. However, this interpretation requires that production in sector 1 could be additively aggregated from a number of micro-production functions - which will only be possible under quite restrictive conditions. Cf., e.g., Felipe and Fisher (2003).

The variable $\alpha$ might also give rise to an interpretation in terms of a federalist structure. Suppose, e.g., that sector 1 is run by local municipalities. Then $(1-\alpha)$ might be viewed as that part of wage taxes that directly flows to municipalities and that would therefore not be regarded as part of the labor costs by local decision makers, while $\alpha$ denotes tax revenues that first flow to a higher tier in the federal system in order to be returned, in a lump-sum fashion, to the local level afterwards. Then the local sector would employ labor on the base of a cost of $w(1-\alpha t)$ per hour.

Using $\alpha$, the cost minimization procedure can be written as:

$$
\min _{L_{1}, K_{1}}\left\{r K_{1}+w(1-\alpha t) L_{1} \mid F^{1}\left(L_{1}, K_{1}\right) \geq \bar{F}^{1}\right\}
$$

and the attending FOC (apart from the output constraint) reads:

$$
\frac{F_{L}^{1}\left(L_{1}, K_{1}\right)}{F_{K}^{1}\left(L_{1}, K_{1}\right)}=\frac{w(1-\alpha t)}{r} .
$$

Denote the solutions to $(7)$ by $K_{1}(\alpha)$ and $L_{1}(\alpha)$. Similarly, we might index all other variables by $\alpha$. From a mathematical perspective, the advantage from using continuous $\alpha$ rather than a dichotomous $\alpha \in\{0,1\}$ lies in making the whole problem differentiable.

Equation (8) together with the output constraint immediately implies that labor input in sector 1 is higher and consequently capital input is lower the larger is $\alpha$, implying that 
labor intensity is ceteris paribus higher when sector 1 is government-owned rather than when it is privatized. We will below show that this pattern also emerges in a general equilibrium.

\subsection{Households and Labor Market}

The economy is populated by one (representative) individual who has preferences over the consumption of goods 1 and 2 and over leisure. We assume that the solution to the utility maximization problem gives rise to a supply function for labor that increases in the net wage rate:

$$
L_{S}=L_{S}[w(1-t)]
$$

with $L_{S}^{\prime}[w(1-t)]>0$. By $w$ we denote the gross wage and by $t$ the tax rate on labor income. Denote by

$$
\eta^{S}:=L_{S}^{\prime} \cdot \frac{w(1-t)}{L_{S}}
$$

the elasticity of labor supply with respect to the net wage.

In a labor market equilibrium the labor intake of the two sectors equals labor supply:

$$
L_{1}+L_{2}=L_{S}[w(1-t)]
$$

\subsection{Government}

Our model is closed by the government budget constraint. Fiscal needs arise from the fact that good 1 is provided to the citizens free of (direct) charge:

- We assume that in the case where production in sector 1 is outsourced to the private sector, the government purchases the output from there. The price for output $\bar{F}^{1}$ has at least to cover the costs of production; otherwise no private supplier can be found, i.e., the procurement costs for $\bar{F}^{1}$ are at least

$$
r \cdot K_{1}(0)+w \cdot L_{1}(0)
$$

Government revenues stem from taxes on employment in the two sectors, i.e., they amount to

$$
t \cdot w \cdot\left(L_{1}(0)+L_{2}(0)\right)
$$


A balanced budget therefore requires

$$
r K_{1}(0)+w(1-t) L_{1}(0)=t w L_{2}(0) .
$$

- Now suppose that production of good 1 takes place in the government sector. From (6), the costs of production amount to $r K_{1}(1)+w(1-t) L_{1}(1)$. Tax revenues only come from labor employed in the production of good 2 (since workers in sector 1 are paid their net wages directly and do not transfer back any money to the government), such that the budget constraint reads:

$$
r K_{1}(1)+w(1-t) L_{1}(1)=t w L_{2}(1)
$$

- which is the same as in the previous case (noting, of course that the input variables may take on different values).

Generalizing with the use of $\alpha$, this does not change; the government budget always has the form:

$$
r K_{1}(\alpha)+w(1-t) L_{1}(\alpha)=t w L_{2}(\alpha)
$$

or, upon using that $r=F_{K}^{2}$ and $L_{2}=L_{S}-L_{1}$,

$$
F_{K}^{2} \cdot K_{1}(\alpha)+w \cdot\left(L_{1}(\alpha)-t L_{S}\right)=0 .
$$

\subsection{Reduced Form}

Summarizing (1) to (4), and incorporating (8) and (9), the equilibrium of the economy can be characterized by the following system of equations:

$$
\begin{aligned}
F_{L}^{1}\left(L_{1}, K_{1}\right) \cdot F_{K}^{2}\left(L_{S}[w(1-t)]-L_{1}, \bar{K}-K_{1}\right) & \\
-F_{K}^{1}\left(L_{1}, K_{1}\right) \cdot w \cdot(1-\alpha t) & =0 \\
F^{1}\left(L_{1}, K_{1}\right)-\bar{F}^{1} & =0 \\
F_{L}^{2}\left(L_{S}[w(1-t)]-L_{1}, \bar{K}-K_{1}\right)-w & =0 \\
F_{K}^{2}\left(L_{S}[w(1-t)]-L_{1}, \bar{K}-K_{1}\right) \cdot K_{1}+w \cdot\left(L_{1}-t L_{S}[w(1-t)]\right) & =0 .
\end{aligned}
$$

The first of these equations is the cost-efficiency condition for the production of good 1 , the second one is the minimal-output requirement for that good, the third one is the 
condition for profit-maximizing labor input in the production of good 2, and the last one is the government budget constraint. Equations (10) through (13) have to be solved for the variables $L_{1}, K_{1}, w$, and $t$ from which all other endogenous variables of the model can then be determined. The solution can be parametrized by $\alpha$.

Observe that an efficient allocation of factors of production requires that the marginal rates of factor substitution are equalized across sectors:

$$
\frac{F_{L}^{1}}{F_{K}^{1}}=\frac{F_{L}^{2}}{F_{K}^{2}} .
$$

In our model, this will happen if and only if $\alpha=0$, i.e., if sector 1 is under private control. ${ }^{5}$

\section{Comparative Statics}

To avoid some technical complications we will henceforth assume that factors of production are complements in both sectors: $F_{K L}^{i}\left(L_{i}, K_{i}\right) \geq 0$ for $i=1,2$. This assumption is, e.g., satisfied for all CES-functions $F=\left(\gamma_{K} \cdot K^{\rho}+\gamma_{L} \cdot L^{\rho}\right)^{1 / \rho}$ with $\rho \leq 1$ and $\gamma_{K}, \gamma_{L}>0$. It implies that a profit maximizing firm in sector $i$ would decrease its demand for a factor whenever the price of the other factor increases.

We derive comparative statics of (10) to (13) with respect to the tax advantage $\alpha$ of public firms. Let us first consider the case of a variable labor supply. In the Appendix, we prove

Proposition 1 Suppose that labor supply is strictly increasing in the net wage, $L_{S}^{\prime}[w(1-$ t) $>>$, and that the equilibrium of the economy exhibits Hicksian stability. Assume further that

- the elasticity of labor supply does not exceed $(1-t) / t$, or

- the tax rate $t$ is small.

Then labor input in sector 1 increases and capital input decreases upon an increase in $\alpha$. The effects on the equilibrium gross wage and the tax rate are generally ambiguous.

\footnotetext{
${ }^{5}$ One could, of course, also nationalize sector 2 to obtain production efficiency. However, this would define away the problem we are interested in.
} 
Observe that the condition $\eta^{S} \leq(1-t) / t$ in Proposition 1 is equivalent to the requirement that the tax elasticity of labor supply is, in absolute terms, less than unity:

$$
\eta_{t}^{S}:=\frac{\partial L_{S}[w(1-t)]}{\partial t} \cdot \frac{t}{L_{S}}=-\frac{t}{1-t} \cdot \eta^{S} \geq-1 .
$$

This is in harmony with stylized facts on labor supply elasticities. Moreover, if this condition were not satisfied, then an increase in $t$ would ceteris paribus reduce wage tax revenue $t w L_{S}[w(1-t)]$. Next consider the case of a fixed labor supply. Setting $L_{S}^{\prime}=0$ in equations (23) to (26) in the proof of Proposition 1 immediately leads to

Proposition 2 Suppose that labor supply is constant, $L^{\prime}=0$, and that the equilibrium exhibits Hicksian stability. Then labor input in sector 1 increases and capital input decreases upon an increase in $\alpha$. The higher $\alpha$, the higher the gross wage, while the effect of $\alpha$ on the equilibrium tax rate is generally unclear.

Propositions 1 and 2 imply that labor input in sector 1 is higher and capital input is lower if the sector is government-run rather than if it is privatized. Hence, the partial effect that, if anything else is equal, tax-favored public production is more labor-intensive than production of the same output in the private sector, generalizes to a general-equilibrium comparison.

Propositions 1 and 2 furthermore imply that the effect of a change in $\alpha$ on the net wage $w(1-t)$ is generally unclear. This observation will play an important role in our discussion below.

\section{Welfare Analysis}

\subsection{The Potential Trade-off}

Should sector 1 be outsourced or government-run? There is a potential trade-off: only if the sector is privatized $(\alpha=0)$, production efficiency in the sense of (14) would be achieved, meaning that the inputs available are used such as to maximize the output of good 2 (recall that the output of good 1 is exogenously fixed). On the other hand, if nationalizing production in sector $1(\alpha=1)$ leads to a higher net wage $w(1-t)$ and, thus, to a larger labor supply, the total amount of available productive resources in the economy increases and output in sector 2 can be augmented. 
An instructive way to view this trade-off is in terms of an Edgeworth box for the production possibilities of the economy:

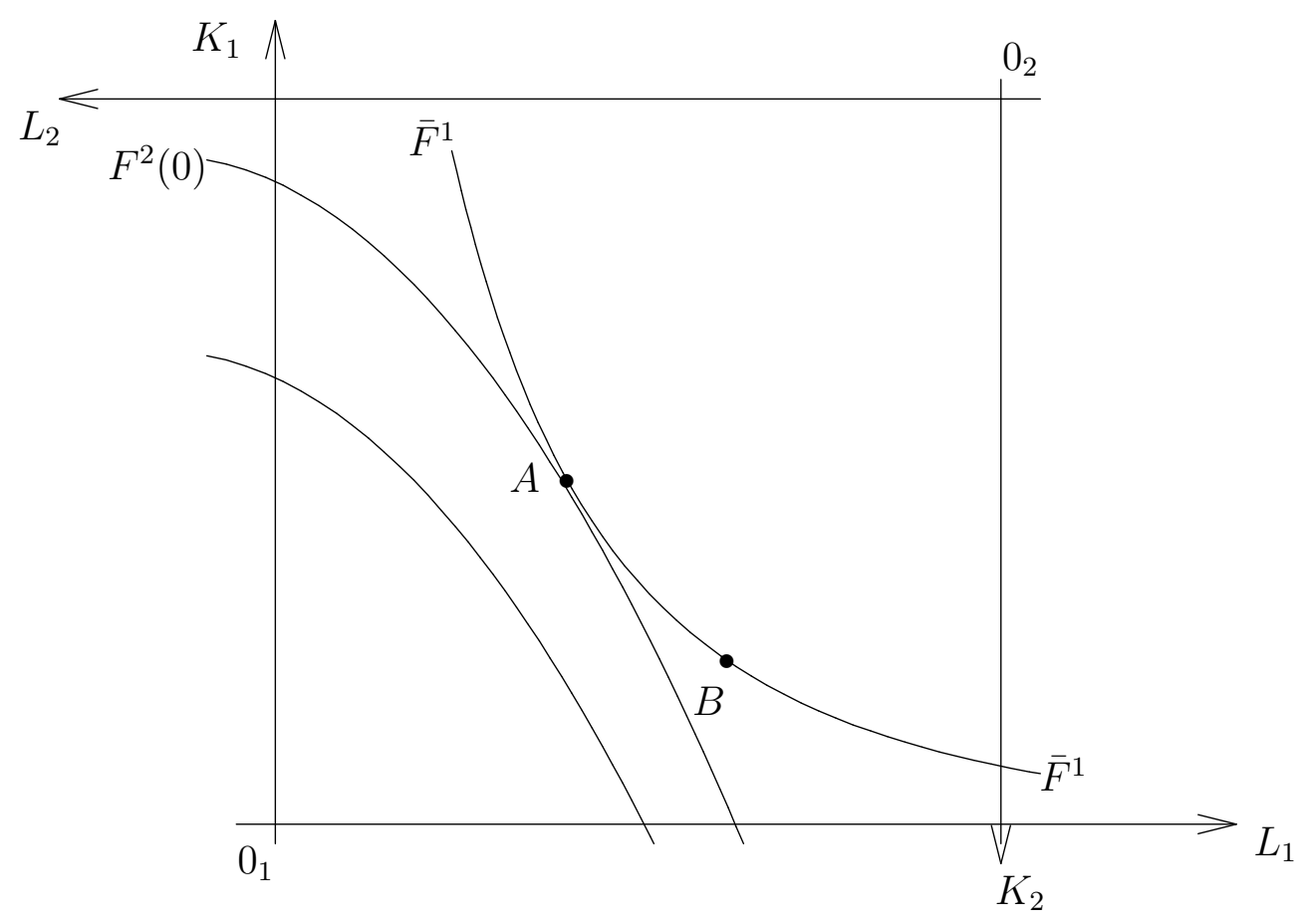

Figure 1

Figure 1 depicts production possibilities for $\alpha=0$ (fully privatized economy). The economy will be in a point like $A$ : Production is efficiently organized - the isoquants of the production functions in sectors 1 and 2 are tangent. The output level in sector 2 is $F^{2}(0)$. The second isoquant for good 2 in Figure 1 represents a higher but unattainable output level.

Figure 2 (see p. 15) depicts production possibilities in the case of $\alpha>0$ (mixed economy), provided that this leads to an increase in the net wage. As a consequence, the width of this Edgeworth box is larger than in Figure 1, reflecting the increase in labor supply. Compared to the box in Figure 1, the origin of sector 2 moves outwards and the previously unattainable output level $F^{2}(\alpha)$ becomes feasible now. However, the economy ends up in a point like $B$ : Sectors 1 and 2 face different factor-price ratios, and consequently isoquants at the equilibrium output levels will intersect rather than being tangent to each other. In a nutshell, the potential difference between a fully private economy (Figure 1) and a mixed economy (Figure 2) boils down to operating efficiently 


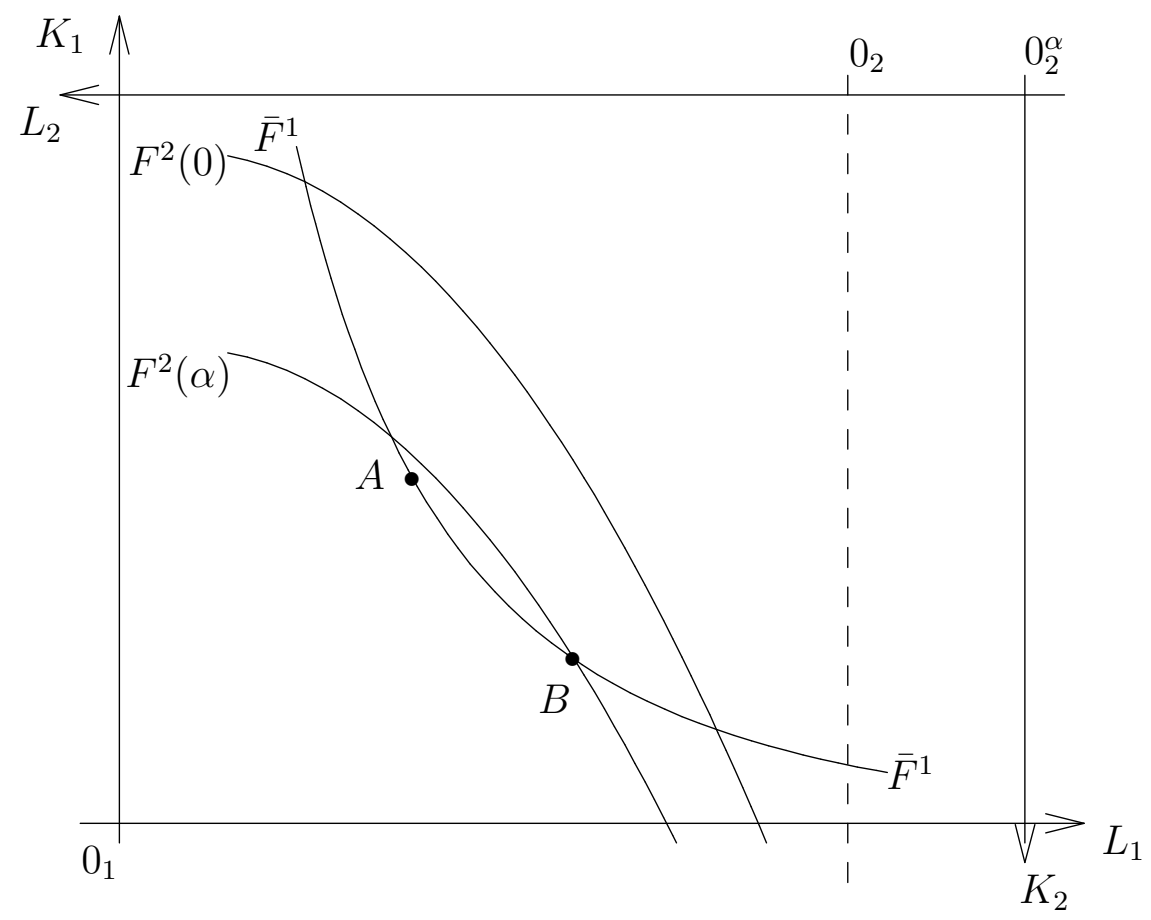

Figure 2

in a "small" Edgeworth box and operating inefficiently in a larger one.

\section{$5.2 \quad$ Fixed Labor Supply}

From Propositions 1 and equation (20), it is unclear whether the case depicted in Figure 2 can at all prevail; it requires an increase in labor supply. Conversely, if labor supply is exogenous, the case of Figure 2 can definitely not occur. Hence,

Proposition 3 If labor supply is fixed $\left(L_{S}^{\prime} \equiv 0\right)$, then fully outsourcing sector 1 (i.e., $\alpha=0)$ is welfare-optimal.

Proof: Both capital and labor are in fixed supply. Efficiency requires (14) to hold, which will only happen if $\alpha=0$.

For the case of variable labor supply (and an increasing net wage), we need to weigh the two elements in the trade-off between intersectoral efficiency and a larger factor supply. Welfare analysis, thus, gets a bit more involved. 


\subsection{Variable Labor Supply}

Recall that underlying our model is a representative household with preferences over the consumed amounts of goods 1 and 2 and leisure. Let us represent these preferences by a standard quasi-concave utility function

$$
U=U\left(c_{1}, c_{2},-L_{S}\right)
$$

where all partial derivatives are positive. Consumption of good 1 equals the exogenous output in sector 1 . The household maximizes utility subject to a budget constraint

$$
c_{2} \leq y+w(1-t) L_{S}
$$

where $y$ denotes income from sources other than labor supply (i.e., capital income and profits, if any, from sector 2 and capital income from sector 1). Optimal labor supply satisfies the FOC:

$$
w(1-t) U_{2}-U_{3}=0
$$

Taking into account that output of good 1 is exogenously fixed, a change in $\alpha$ will then lead to an increase in utility if and only if

$$
\frac{\mathrm{d} U}{\mathrm{~d} \alpha}=U_{2} \cdot \frac{\mathrm{d} c_{2}}{\mathrm{~d} \alpha}-U_{3} \cdot \frac{\mathrm{d} L_{S}}{\mathrm{~d} \alpha}=U_{2} \cdot\left(\frac{\mathrm{d} c_{2}}{\mathrm{~d} \alpha}-w(1-t) \cdot \frac{\mathrm{d} L_{S}}{\mathrm{~d} \alpha}\right)>0
$$

where we used (15). Hence, we have to check for conditions such that

$$
\frac{\mathrm{d} c_{2}}{\mathrm{~d} \alpha}>w(1-t) \cdot \frac{\mathrm{d} L_{S}}{\mathrm{~d} \alpha}
$$

In an equilibrium, consumption of good 2 equals production of that good, i.e., $c_{2}=$ $F^{2}\left(K_{2}, L_{2}\right)$. If we vary $\alpha$, output in sector 2 is affected as follows:

$$
\begin{aligned}
\frac{\mathrm{d} F^{2}}{\mathrm{~d} \alpha} & =F_{L}^{2} \cdot \frac{\mathrm{d} L_{2}}{\mathrm{~d} \alpha}-F_{K}^{2} \frac{\mathrm{d} K_{1}}{\mathrm{~d} \alpha} \\
& =\left(\frac{F_{K}^{2} F_{L}^{1}}{F_{K}^{1}}-F_{L}^{2}\right) \frac{\mathrm{d} L_{1}}{\mathrm{~d} \alpha}+F_{L}^{2} \frac{\mathrm{d} L_{S}}{\mathrm{~d} \alpha}=w\left(\frac{\mathrm{d} L_{S}}{\mathrm{~d} \alpha}-\alpha t \cdot \frac{\mathrm{d} L_{1}}{\mathrm{~d} \alpha}\right) \\
& =w\left(\frac{\mathrm{d} L_{S}}{\mathrm{~d} \alpha}-\alpha t \cdot \frac{\mathrm{d} L_{1}}{\mathrm{~d} \alpha}\right) .
\end{aligned}
$$

Here we invoked $\mathrm{d} K_{1} / \mathrm{d} \alpha=-(1-\alpha t)\left(F_{L}^{2} / F_{K}^{2}\right)\left(\mathrm{d} L_{1} / \mathrm{d} \alpha\right)$. If labor supply is fixed $\left(\mathrm{d} L_{S}=\right.$ $0)$, then output in sector 2 decreases whenever production of good 1 is nationalized. This is intuitive: For $\alpha \neq 0$, the factor allocation will be inefficient. With a fixed output $\bar{F}^{1}$ 
and fixed supplies of both factors, output in sector 2 cannot but decline (as shown in Proposition 3). A negative impact of $\alpha$ on labor supply would acerbate this effect; only with a positive impact on labor supply can the effect be turned around.

Plugging (17) into (16), we find that welfare improves with an increase in $\alpha$ if and only if:

$$
\begin{aligned}
w\left(\frac{\mathrm{d} L_{S}}{\mathrm{~d} \alpha}-\alpha t \frac{\mathrm{d} L_{1}}{\mathrm{~d} \alpha}\right) & >w(1-t) \cdot \frac{\mathrm{d} L_{S}}{\mathrm{~d} \alpha} \\
\frac{\mathrm{d} L_{S}}{\mathrm{~d} \alpha} & >\alpha \cdot \frac{\mathrm{d} L_{1}}{\mathrm{~d} \alpha} .
\end{aligned}
$$

Condition (18) provides a simple requirement for an increase in $\alpha$ to be welfareimproving: The effect of such a change on labor supply must exceed $\alpha$ times the effect on labor intake in sector 1 . This condition links the increase in the labor supply to the tax wedge and the distortion in the factor mix which arises from the tax advantage of the public sector. The left-hand side of (18) is the increase in the total labor supply as a result of the public sector tax advantage, corresponding to an increase in the size of the Edgeworth box. The right-hand side of (18) relates to the distortion inside the Edgeworth box. The distortion in the allocative efficiency caused by a change in the demand for labor in sector 1 is increasing in the tax advantage of the public sector, measured by $\alpha$. Therefore, a higher tax wedge requires a proportionally larger increase in the aggregate labor supply in order to improve welfare.

An immediate consequence of this observation is that, starting from a fully privatized economy $(\alpha=0)$, an increase in $\alpha$ will be welfare-improving if and only if it leads to an increase in labor supply or, which is the same, to an increase in the net wage.

Observe that (18) can equivalently be written as

$$
\frac{\mathrm{d}[w(1-t)]}{\mathrm{d} \alpha}>\frac{\alpha}{L_{S}^{\prime}} \cdot \frac{\mathrm{d} L_{1}}{\mathrm{~d} \alpha}
$$

Given that $\mathrm{d} L_{1} / \mathrm{d} \alpha>0$ is plausible from Proposition 1, condition (19) conveys that a welfare improvement is possible only if the net wage increases - and increases sufficiently sharply - upon an increase in $\alpha$ (or, conversely, if outsourcing production of good 1 from the government into the private sector leads to a sufficiently large drop in after-tax wages).

It is interesting to observe that whenever outsourcing would decrease the wage rate it can never be optimal to fully privatize sector 1: The LHS in (19) is always larger than zero. We sum this up in 
Proposition 4 Full outsourcing can never be optimal if it leads to a decrease in net wages.

Increasing $\alpha$ is welfare-improving if it leads to a sufficiently large increase in the aftertax wage.

Proposition 4 is a typical second best result: With variable labor supply, wage taxation is distortionary in the sense that the marginal rate of substitution between leisure and the consumption of good $2, U_{3} / U_{2}=w(1-t)$, does not equal the marginal productivity of labor in the production of good $2, F_{L}^{2}=w$. It may then not be optimal to achieve production efficiency. Violations of condition (14) can be induced by giving sector 1 a tax advantage over sector 2, which in our framework is tantamount to (partly) have this sector government-operated. One visible impact of such a policy is then a higher labor intensity of the public sector, relative to what a private enterprise would choose to have.

Proposition 4 states conditions such that full privatization $(\alpha=0)$ is not optimal. This does, however, not imply that welfare increases when the government fully takes over sector $1(\alpha=1)$. Rather, intermediate values of $\alpha$ might dominate the polar cases. As outlined above, one way to think of such intermediate values is in terms of a mixed personnel structure (both civil servants and normal employees) or of partial privatization. Then Proposition 4 conveys that entirely staffing sector 1 with normal employees (represented by $\alpha=0$ ) is not optimal, but that to have some tax-favored civil servants $(\alpha>0)$ might actually be preferable. An alternative interpretation is that the mechanism that we identify provides an efficiency argument in favor of a federal structure in which lower-level governments receive a certain fraction of (centrally administered) wage tax revenues. This gives them a potentially welfare-improving tax advantage over the private sector. As a 100\%-tax advantage $(\alpha=1)$ will, in general, not be optimal, our results also suggest an efficiency explanation for a certain degree of fiscal churning in which the federal government would collect a share $(1-\alpha)$ of the tax revenue and return it to lower-level governments as lump-sum transfers.

\subsection{The Role of the Labor Supply Elasticity}

The crucial question arising from Proposition 4 is, of course, whether the net wage does at all (and then sufficiently steeply) increase in response to increases in $\alpha$. From Proposition 1 this is not clear. 
To gain further insights on this question, combine (25) and (26)), where we use $\beta$ as defined in (22) in the Appendix:

$$
\begin{aligned}
\frac{\mathrm{d}[w(1-t)]}{\mathrm{d} \alpha}= & (1-t) \cdot \frac{\mathrm{d} w}{\mathrm{~d} \alpha}-w \cdot \frac{\mathrm{d} t}{\mathrm{~d} \alpha} \\
= & -\beta \cdot w \cdot\left(-2(1-t) L_{S}^{\prime} F_{L}^{1} F_{K}^{2} F_{L L}^{2}+\left(L_{S}-L_{1}\right) \cdot\left[F_{K}^{1} F_{L L}^{2}-F_{L}^{1} F_{K L}^{2}\right]\right. \\
& \left.\quad+F_{K}^{1} \cdot\left[w-F_{K L}^{2} K_{1}\right]-F_{L}^{1} \cdot\left[F_{K}^{2}-K_{1} F_{K K}^{2}\right]\right) \\
= & -\beta \cdot w \cdot(\underbrace{-2(1-\alpha t) \cdot \eta^{S} \cdot L_{S} F_{L L}^{2} F_{K}^{1}}_{\geq 0}+\underbrace{\left(L_{S}-L_{1}\right) \cdot\left[F_{K}^{1} F_{L L}^{2}-F_{L}^{1} F_{K L}^{2}\right]}_{<0} \\
& \left.+w \cdot(\underbrace{\alpha t F_{K}^{1}}_{>0, \text { small }}+K_{1} \cdot \underbrace{\left[F_{L}^{1} F_{K K}^{2}-F_{K}^{1} F_{K L}^{2}\right]}_{<0})\right) .
\end{aligned}
$$

To arrive at the final line of $(20)$, we made use of $F_{K}^{1} w-F_{L}^{1} F_{K}^{2}=F_{K}^{1} \cdot\left[w-r F_{L}^{1} / F_{K}^{1}\right]=$ $F_{K}^{1} w \alpha t$ which stems from (2), (3), and (7).

Combining (19) and (20), one sees opposing forces at work: For a welfare improvement, (20) must, according to (19), exceed $\mathrm{d} L_{1} / \mathrm{d} \alpha \cdot \alpha / L_{S}^{\prime}$ which is positive whenever $\mathrm{d} L_{1} / \mathrm{d} \alpha>0$. Expression (20) is smaller and, thus, more likely to be negative if labor supply elasticity is higher (the cofactor of $\eta^{S}$ is negative). Thus, for high values of $\eta^{S}$, (19) cannot be satisfied. On the other hand, if $\eta^{S}$ is getting very small, the RHS of (19) exceeds all bounds, making it again impossible for the condition to hold. ${ }^{6}$

While this observation renders general results for an optimal value of $\alpha$ unobtainable, we can at least state that for low but positive labor supply elasticities a zero value for $\alpha$ cannot be optimal. To see this, recall from (19) that an increase in the net wage suffices to make deviations from $\alpha=0$ worthwhile. From (20), this will happen in the case of positive, but small labor-supply elasticities. We summarize:

Proposition 5 Full privatization $(\alpha=0)$ can never be optimal if the labor supply elasticity is positive but small.

\section{Conclusion}

In this paper, we analyze the relationship between privatization and taxation from a general-equilibrium perspective. We take as our starting point that several publicly pro-

\footnotetext{
${ }^{6}$ This point could already be seen from (18): if the elasticity of labor supply is too small then (18) cannot hold as its LHS approaches zero, while its RHS does not.
} 
vided goods and services, like hospitals, schools, and public transportation, can be produced privately, even if they would be ultimately financed by the government. Empirical evidence suggests that outsourcing or privatizing such activities tends to result in a leaner workforce and increasing capital intensity in their production. This is often viewed as evidence of slack in public production. We show that this need not be the case when governmental entities operate under a different tax structure with respect to factor inputs than private firms: In a consolidated government budget, the government "pays taxes to itself". As a consequence, when a government entity purchases factor inputs, its true factor costs are the factor returns net of the taxes it collects rather than the tax-inclusive factor prices which underlie the cost calculations in private firms. This implies that the government sector has a cost advantage over the private sector for that factor that is taxed relatively more heavily. As - in our model, but also in most countries - labor is taxed more heavily than capital, the government would then optimally organize production in a more labor-intensive way than a private firm. Put differently: Observing a different factor mix in private and public production need not be indicative of wasteful slack in the government sector but may well be the entirely optimal response to tax-induced differences in factor price ratios.

Moreover, it is not at all evident that different factor price ratios and, therefore, different marginal rates of technical substitution in public and private production are an evil. We identify a key tradeoff in deciding whether to fully privatize or outsource government activities or not. On the one hand, different factor prices faced by public and private entities distort allocative efficiency. In a mainly market-based economy, this would call for fully outsourcing production from the tax-sheltered realm of government. On the other hand, a higher labor-intensity of government-run activities may serve as a countervailing distortion in the presence of distorting wage taxation. Outsourcing government production and then letting the government re-purchase the output may, under certain circumstances, result in a decrease in equilibrium net wages and, thus a reduction in labor supply. If the reduction in production possibilities associated with this is sufficiently severe it may well prove beneficial to incur the production inefficiencies in a mixed economy with a private and a tax-favored public sector, compared to a production-efficient economy with smaller production possibilities. Given that these effects are driven by changes in labor supply, we argue that full privatization is never optimal with positive but low 
labor supply elasticities, as in Europe. On the other hand, if labor supply is fixed, then full privatization would be efficient.

Our findings provide an efficiency-argument in favor of otherwise-puzzling tax advantages given to public employees in some countries, like Germany, Italy and Austria. There, civil servants are subject to social security taxation only to a lesser extent than normal employees, rendering them cheaper to hire for the government than standard employees. Such an arrangement may be efficient at least to some degree when labor supply is elastic.

For public production that takes place at lower-level jurisdictions in federations our analysis also suggests an efficiency argument for the otherwise puzzling phenomenon of fiscal churning where the central government collects a share of tax revenues and return it as lump-sum transfers to all lower-level jurisdictions, and not just to poorer ones. We identify that, even though full outsourcing would not be generally efficient, giving the public sector a full tax advantage could be inefficient as well. Fiscal churning can then be understood as an attempt to influence the price that lower-level jurisdisctions effectively face when financing their production activities.

Our findings also suggest a number of empirically testable predictions: With any level of wage taxation, countries where lower-level governments are able to keep a larger share of wage tax revenues should have more labor-intensive public production at that level. Conversely, changes in revenue-sharing between central and lower level governments should have implications for labor-intensity of the public sector at the lower level governments. Public production in countries that organize their public finances in a single consolidated budget should be more labor intensive than in countries with a fragmented government accounting and a larger number of separate budgetary entities. With fragmented public finances, cost-minimizing budget planners in lower-level governments or federal agencies take into account only their share of public sector tax advantage. Furthermore, to perceive the true extent of the government's tax advantage over the private sector personnel recruiters in countries with fragmented accounting have to see through more complex budgetary mechanics than in countries with more aggregate budgeting.

There are several ways in which our analysis could be extended. One might consider a small open economy where the rental rate of capital is exogenously given. Moreover, one could dispense with the assumption that governments are price takers in the factor markets. While this is an appropriate assumption in the case of local municipalities and 
individual government agencies, it is implausible for the central level of government as a whole. These extensions, as well as empirical testing of the predictions and evaluation of quantitative importance of our findings, are left for further research.

\section{Acknowledgements}

Great parts of this paper were written while Andreas Wagener visited the Centre for Economic and Business Research (CEBR) in Copenhagen. He wishes to thank CEBR for its outstanding hospitality. Financial support from the Danish Social Science Research Council is gratefully acknowledged. Seminar and conference participants in Vienna, Bangkok, Beijing, Munich, and Dresden provided valuable comments and stimulating criticism.

\section{Appendix: Proof of Proposition 1}

Proof: Differentiating (10) to (13) with respect to $\alpha$ yields the following system of equations:

$$
\left(\begin{array}{cccc}
a_{1} & a_{2} & a_{3} & a_{4} \\
b_{1} & b_{2} & 0 & 0 \\
c_{1} & c_{2} & c_{3} & c_{4} \\
d_{1} & d_{2} & d_{3} & d_{4}
\end{array}\right) \cdot\left(\begin{array}{c}
\mathrm{d} L_{1} \\
\mathrm{~d} K_{1} \\
\mathrm{~d} w \\
\mathrm{~d} t
\end{array}\right)=\left(\begin{array}{c}
-w t F_{K}^{1} \\
0 \\
0 \\
0
\end{array}\right) \cdot \mathrm{d} \alpha
$$


with

$$
\begin{aligned}
& a_{1}=F_{L L}^{1} F_{K}^{2}-F_{L}^{1} F_{K L}^{2}-F_{K L}^{1} w(1-\alpha t)<0 \\
& a_{2}=F_{K L}^{1} F_{K}^{2}-F_{L}^{1} F_{K K}^{2}-F_{K K}^{1} w(1-\alpha t) \\
& a_{3}=(1-t) F_{L}^{1} F_{K L}^{2} L_{S}^{\prime}-F_{K}^{1}(1-\alpha t) \\
& a_{4}=-w F_{L}^{1} F_{K L}^{2} L_{S}^{\prime}+F_{K}^{1} w \alpha \\
& b_{1}=-F_{L}^{1} \\
& b_{2}=-F_{K}^{1}<0 \\
& c_{1}=-F_{L L}^{2} \\
& c_{2}=-F_{L K}^{2} \\
& c_{3}=F_{L L}^{2} L_{S}^{\prime}(1-t)-1<0 \\
& c_{4}=-F_{L L}^{2} L_{S}^{\prime} w \\
& d_{1}=w-K_{1} F_{K L}^{2} \\
& d_{2}=F_{K}^{2}-K_{1} F_{K K}^{2} \\
& d_{3}=-t L_{S}+L_{1}-w t L_{S}^{\prime}(1-t)+K_{1} F_{K L}^{2} L_{S}^{\prime}(1-t) \\
& d_{4}=-w L_{S}+w^{2} t L_{S}^{\prime}-K_{1} F_{K L}^{2} L_{S}^{\prime} w .
\end{aligned}
$$

Denote the matrix on the LHS of (21) by $A$. Observe that we arranged the matrix such that the diagonal elements $a_{1}, b_{2}$, and $c_{3}$ are negative. Also $d_{4}$ will be negative for small values of $t$ or, as long as $t \leq 0.5$ if the elasticity of labor supply is below unity. In order for the system to be perfectly stable (i.e., stable in the Hicksian sense), $A$ must then be negative semi-definite (see Takayama, 1985 , pp. 313ff). In particular, $\operatorname{det} A>0$ — which we will henceforth assume. For sake of abbreviation define:

$$
\beta:=\frac{w t F_{K}^{1}}{\operatorname{det} A}>0
$$


where the positive sign prevails when $A$ is stable. Now apply Cramer's Rule to (21):

$$
\begin{aligned}
\frac{\mathrm{d} L_{1}}{\mathrm{~d} \alpha}= & \beta \cdot\left(c_{3} d_{4}-c_{4} d_{3}\right) \cdot F_{K}^{1} \\
= & \beta \cdot w \cdot\left(L_{S}-L_{S}^{\prime} w t+L_{S}^{\prime} \cdot\left[-F_{L L}^{2}\left(L_{S}-L_{1}\right)+K_{1} F_{K L}^{2}\right]\right) \cdot F_{K}^{1} \\
= & \beta \cdot w \cdot\left(L_{S} \cdot\left[1-\eta^{S} \cdot \frac{t}{1-t}\right]+L_{S}^{\prime} \cdot\left[-F_{L L}^{2}\left(L_{S}-L_{1}\right)+K_{1} F_{K L}^{2}\right]\right) \cdot F_{K}^{1} \\
\frac{\mathrm{d} K_{1}}{\mathrm{~d} \alpha}= & -\beta \cdot\left(c_{3} d_{4}-c_{4} d_{3}\right) \cdot F_{L}^{1}=-\frac{F_{L}^{1}}{F_{K}^{1}} \cdot \frac{\mathrm{d} L_{1}}{\mathrm{~d} \alpha} \\
\frac{\mathrm{d} w}{\mathrm{~d} \alpha}= & -\beta \cdot\left(b_{2}\left(c_{4} d_{1}-c_{1} d_{4}\right)+b_{1}\left(c_{2} d_{4}-c_{4} d_{2}\right)\right) \\
= & -\beta \cdot w \cdot\left(L_{S}^{\prime} \cdot\left[\Gamma-F_{L}^{1} F_{K}^{2} F_{L L}^{2}\right]+L_{S} \cdot\left[F_{K}^{1} F_{L L}^{2}-F_{L}^{1} F_{K L}^{2}\right]\right) \\
\frac{\mathrm{d} t}{\mathrm{~d} \alpha}= & -\beta \cdot\left(b_{2}\left(c_{1} d_{3}-c_{3} d_{1}\right)+b_{1}\left(c_{3} d_{2}-c_{2} d_{3}\right)\right) \\
= & -\beta \cdot\left((1-t) L_{S}^{\prime} \cdot\left[\Gamma+F_{L}^{1} F_{K}^{2} F_{L L}^{2}\right]+\left(L_{1}-t L_{S}\right) \cdot\left[F_{K}^{1} F_{L L}^{2}-F_{L}^{1} F_{K L}^{2}\right]\right. \\
& \left.-F_{K}^{1} \cdot\left(w-K_{1} F_{K L}^{2}\right)+F_{L}^{1} \cdot\left(F_{K}^{2}-K_{1} F_{K K}^{2}\right)\right)
\end{aligned}
$$

where we defined:

$$
\Gamma:=w(1-t) F_{K}^{1} F_{L L}^{2}+F_{L}^{1} \cdot\left(K_{1} \cdot\left[F_{K K}^{2} F_{L L}^{2}-\left(F_{K L}^{2}\right)^{2}\right]+w t F_{K L}^{2}\right)
$$

which is of ambiguous sign. Given the assumptions mentioned in the proposition, the signs of (23) and (24) turn out as asserted, while the signs of (25) and (26) remain unclear in general.

\section{References}

Cardona, Francisco, 2002, Scope of Civil Services in European Countries. OECD: Paris. http://www.oecd.org/dataoecd/44/331850438.pdf.

Dewenter, Kathryn L., and Paul H. Malatesta, 2001, State-Owned and Privately-Owned Firms: An Empirical Analysis of Profitability, Leverage, and Labor Intensity. American Economic Review 91, 320-334.

Felipe, Jesus and Franklin M. Fisher, 2003, Aggregation in Production Functions: What Applied Economists Should Know. Metroeconomica 54, 208-262. 
Gordon, Roger H., 2003, Taxes and Privatization, in: Cnossen, Sijbren and Hans-Werner Sinn (eds.), Public Finance and Public Policy in the New Century. The MIT Press: Cambridge (Mass.), 185-211.

Gordon, Roger H., Ching-En Bai, and David D. Li, 1999, Efficiency Losses from Tax Distortions vs. Government Control. European Economic Review 43, 1095-1113.

Huizinga, Harry, and Nielsen, Søren Bo, 2001, Privatization, Public Investment, and Capital Income Taxation. Journal of Public Economics 82, 399-414.

La Porta, Rafael and Florencio Lòpez-de-Silanes, 1999, Benefits of Privatization - Evidence from Mexico. Quarterly Journal of Economics 114, 1193-1242.

Megginson, William L., Robert C. Nash, and Matthias van Randenborgh, 1994, The Financing and Operating Performance of Newly Privatized Firms: An International Empirical Analysis. Journal of Finance 44, 403 - 452.

Megginson, William L., and Jeffry M. Netter, 2001, From State to Market: A Survey of Empirical Studies on Privatization. Journal of Economic Literature 39, 321 - 389.

Mintz, Jack M., Duanjie Chen, and Evangelia Zorotheos, 2000, Taxing Issues with Privatization. A Checklist. Policy Research Working Paper No. 2348. The World Bank, Country Economics Department: Washington, D.C.

Schiavo-Campo, Salvatore, Giulio de Tommaso, and Amitabha Mukherjee, 2003, An International Statistical Survey of Government Employment and Wages. The World Bank (Public Sector Management and Information Technology Team): Washington D.C.

Shleifer, Andrei, 1998, State versus Private Ownership. Journal of Economic Perspectives 12, 133-150. 
Takayama, Akira, 1985, Mathematical Economics. Second edition. Cambridge University Press: Cambridge.

Toninelli, Pier Angelo (ed.), 2000, The Rise and the Fall of State-Owned Enterprise in the Western World. Cambridge University Press: Cambridge.

Wassenaar, M.C. and R.H.J.M. Gradus, 2004, Contracting Out: The Importance of a Solution for the VAT Distortion. CESifo Economic Studies 20, 377-396. 